\title{
Platelet Distribution Width and Mean Platelet Volume Are Not Correlated with the Disease Activity Indices of Ankylosing Spondylitis
}

\author{
Sejin Byun, Seung Min Jung, Jason Jungsik Song, Yong-Beom Park, Sang-Won Lee \\ Division of Rheumatology, Department of Internal Medicine, Yonsei University College of Medicine, Seoul, Korea
}

\begin{abstract}
Objective. We investigated the association of platelet distribution width (PDW) and mean platelet volume (MPV) with disease activity indices of ankylosing spondylitis (AS) in patients whose laboratory results or medical conditions would not affect PDW and MPV levels. Methods. We analysed demographic and laboratory data of 88 patients with AS. On the same day as the laboratory tests were done, we assessed AS disease activity using the Bath Ankylosing Spondylitis Disease Activity Index, Bath Ankylosing Spondylitis Functional Index, Bath Ankylosing Spondylitis Patients Global Score and Ankylosing Spondylitis Disease Activity Score (ASDAS), including erythrocyte sedimentation rate (ESR) (ASDAS-ESR) and C-reactive protein (CRP) (ASDAS-CRP). The association was analyzed by linear regression. Results. The median age of 88 patients was 38.0 years and the median length of observation was 5.5 years. The median platelet count was $266,500.0 / \mu \mathrm{L}$, the median PDW was $10.7 \mathrm{fL}$ and the median MPV $9.6 \mathrm{fL}$. The median ESR was $19.0 \mathrm{~mm} / \mathrm{hr}$ and CRP was $2.5 \mathrm{mg} / \mathrm{L}$. Among acute reactants, only CRP was negatively correlated with MPV, but not PDW $(r=-0.218, \mathrm{p}<0.041)$. However, both PDW and MPV were not significantly correlated with any disease activity index of AS. On multivariate linear regression analysis, only the length of observation was significantly correlated with MPV $(\beta=0.224, \mathrm{p}<0.044)$. Conclusion. PDW and MPV were not potent surrogate markers to reflect AS activity, with potential confounding strictly controlled, to affect MPV and PDW levels. (J Rheum Dis 2017;24:143-148)
\end{abstract}

Key Words. Mean platelet volume, Platelt count, Ankylosing spondylitis

\section{INTRODUCTION}

Ankylosing spondylitis (AS) is a systemic autoimmune disease, which is characterised by both articular and extra-articular features [1]. In the clinical settings, erythrocyte sedimentation rate (ESR) or C-reactive protein (CRP) are widely measured to assess the inflammatory burdens in many rheumatic diseases, but, in AS patients, either ESR or CRP alone has not been considered good predictors to reflect AS activity [2,3]. Moreover, on the basis of clinical symptoms, function and spinal mobility, various tools to assess the disease activity of AS have been introduced and used including bath ankylosing spondylitis disease activity index (BASDAI), bath ankylosing spondylitis functional index (BASFI) and bath ankylosing spondylitis patients global score (BAS-G), Bath Ankylosing Spondylitis Metrology Index. However, these indices also have a limitation that they include no objective laboratory results [4-7]. In 2009, ankylosing spondylitis disease activity score (ASDAS) with ESR (ASDAS-ESR) and CRP (ASDAS-CRP), including both clinical and laboratory items, was proposed [8]. Nevertheless, a need for a single and convenient serum marker to predict AS activity has been still raised to date. Platelet distribution width (PDW) and mean platelet volume (MPV) are the surrogate indices to reflect size distribution of platelets in peripheral circulation. They can be increased in idiopathic thrombocytopenic purpura and myeloproliferative disorder, and decreased in aplastic anaemia $[9,10]$. In addition, there were reports that PDW

Received : March 14, 2017, Revised : May 1, 2017, Accepted : May 10, 2017

Corresponding to : Sang-Won Lee, Division of Rheumatology, Department of Internal Medicine, Yonsei University College of Medicine, 50-1 Yonsei-ro, Seodaemun-gu, Seoul 03722, Korea. E-mail : sangwonlee@yuhs.ac 
and MPV can also reflect the inflammatory burdens in various pathological situations, such as abnormal glucose metabolism, chronic liver diseases, chronic kidney diseases, hypertension, dyslipidaemia, cardiovascular diseases, and rheumatoid arthritis [11-17]. However, previous studies regarding the clinical efficiency of PDW and MPV to reflect AS activity reported inconsistent results, and furthermore, they did not strictly control the confounding factors to affect PDW and MPV [18-22]. In this study, we investigated whether PDW and MPV can reflect disease activity indices of AS in patients without abnormal laboratory results or medical conditions to affect PDW and MPV levels.

\section{MATERIALS AND METHODS}

\section{Patients}

We consecutively screened and enrolled 141 patients with AS in this study, from March 2015 to October 2015, by the inclusion criteria as follows: (1) patients who fulfilled modified New York criteria for AS and who had been first diagnosed with AS at the Division of Rheumatology, Yonsei University College of Medicine, Severance Hospital [23]; (2) patients who had no medical conditions to affect PDW and MPV, such as abnormal glucose metabolism, chronic liver diseases, chronic kidney diseases, hypertension, dyslipidaemia, cardiovascular diseases, rheuma- toid arthritis, and concurrent infection or hematologic disorders identified by 10th revised international classification of diseases [11-17,24,25]; (3) patients who had never received medications for diseases above searched by the Korean Drug Utilization Review system; (4) patients who had not received blocking agents against tumour necrosis factor (TNF), which are one of factors influencing the maturation of thrombopoietic cells and release of platelet into the circulation [26]. (5) Patients who had no concurrent infection and malignancy to enhance acute phase reactants levels; (6) patients who gave informed consent to their participation; (7) patients who took the assessment of disease activity indices of AS by independent physician on the same day of laboratory tests; (8) patients having laboratory results fulfilling the normal reference range as described in Figure 1 [27]. We excluded 28 patients having medical conditions or having received anti-TNF agents to affect PDW and MPV, and we further excluded 32 according to the inclusion criteria based on laboratory results (Figure 1). Finally, we analysed data of 88 patients with AS in this study. This study was approved by the Institutional Review Board of Severance Hospital. Informed consent was obtained from all patients (4-2015-0826).

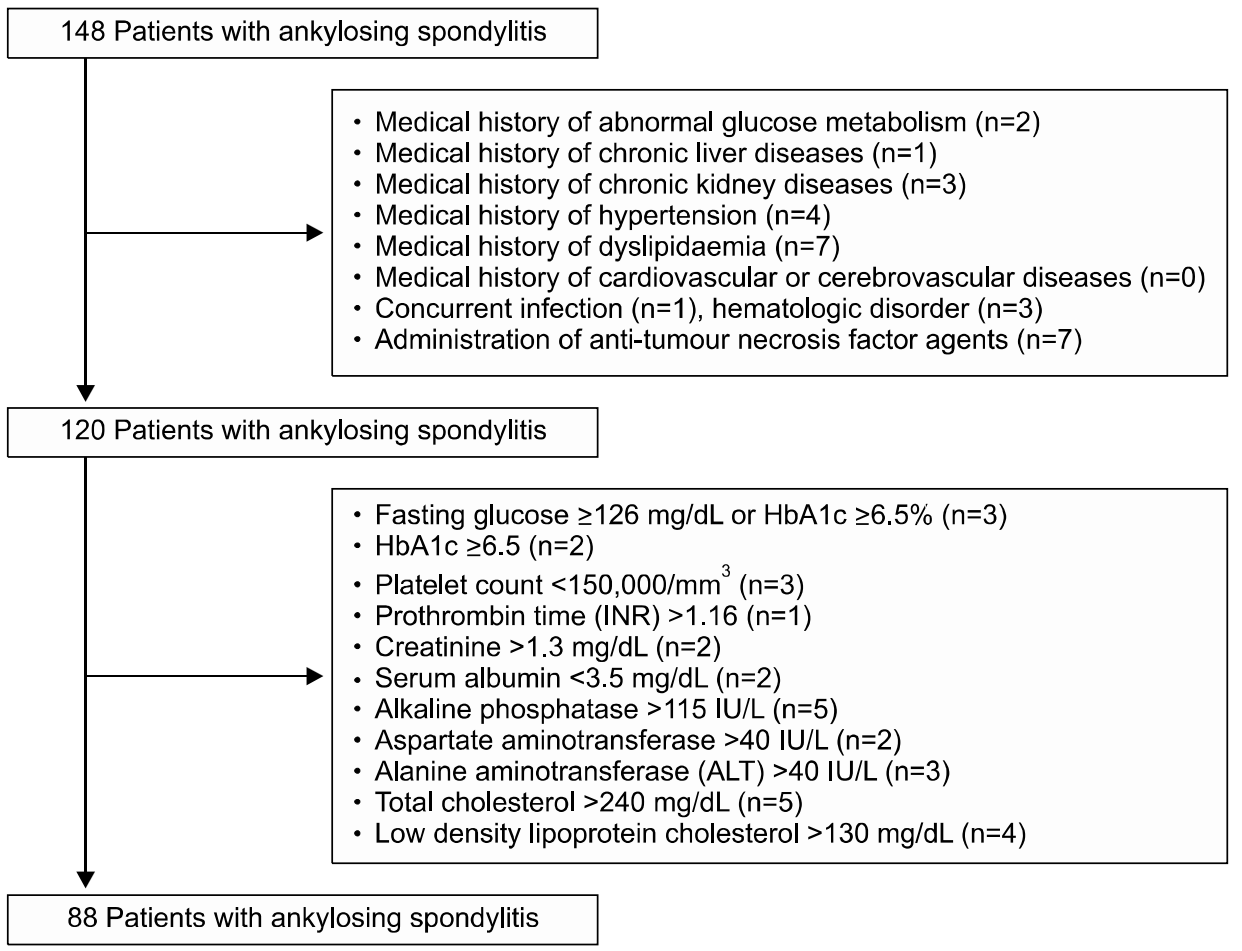

Figure 1. Selection of the study population. HbA1c: haemoglobin A1c, INR: international normalized ratio. 


\section{Data collection and assessment of the disease activity of AS}

On the same day of laboratory tests, we measured blood pressure as well as height and weight to calculate body mass index (BMI). Smoking history was assessed via self-reported questionnaire for patients. Age, gender and the follow-up duration were obtained as demographic data. We described the items of laboratory tests in Table 1. Ethylenediaminetetraacetic acid was currently used as anticoagulant. PDW and MPV were routinely measured and calculated by automatic cell counters after $120 \mathrm{mi}-$ nutes from the time of blood collection in all cases in order to minimize the chance of platelet swelling. We assessed the disease activity of AS using BASDAI, BASFI, and BAS-G [4-6]. We also collected ASDAS-ESR and ASDAS-CRP by the equations as described in a previous study [8].

\section{Statistical analysis}

All statistical analyses were conducted using SPSS software (version 23 for Windows; IBM Corp., Armonk, NY, USA). Results of continuous variables were expressed as median (interquartile range). Univariate analysis of the association of variables with ASDAS-ESR and ASDAS-CRP was performed using linear regression test. Standardized correlation coefficient was assessed by a multivariate linear regression test using variables with significant differences on univariate analysis. The p-values less than 0.05 were considered to indicate statistical significance.

\section{RESULTS}

\section{Baseline characteristics of patients with ankylosing spondylitis}

The baseline characteristics are summarized in Table 1. The median age of 88 participants ( 68 men and 20 women) was 38.0 years and the median follow-up duration was 5.5 years. The median BMI was $24.0 \mathrm{~kg} / \mathrm{m}^{2}$. Thirty-six patients reported the smoking history. The median platelet count was $266,500.0 / \mu \mathrm{L}$ and the median PDW and MPV were $10.7 \mathrm{fL}$ and 9.6fL, respectively. The median ESR and CRP were $19.0 \mathrm{~mm} / \mathrm{hr}$ and $2.5 \mathrm{mg} / \mathrm{L}$. The median BASDAI, BAS-G, and BASFI were assessed as 3.6, 3.0 and 1.7, respectively. And the median ASDAS-ERS and ASDAS-CRP were 2.3 and 2.0.

\section{Univariate and multivariate analyses of PDW and other variables}

We analysed the association of PDW with acute phase reactants and the disease activity indices of AS. Univariate linear regression analysis revealed that PDW was inversely correlated with platelet count $(r=-0.369, \mathrm{p}<0.001)$, and

Table 1. Baseline characteristics of patients with ankylosing spondylitis $(\mathrm{n}=88)$

\begin{tabular}{|c|c|}
\hline Variable & Value \\
\hline \multicolumn{2}{|l|}{ Demographic data } \\
\hline Age $(y r)$ & $38.0(15.8)$ \\
\hline Male gender & $68(77.3)$ \\
\hline Follow-up duration (yr) & $5.5(8.5)$ \\
\hline Smoking & $36(40.9)$ \\
\hline $\mathrm{BMI}\left(\mathrm{kg} / \mathrm{m}^{2}\right)$ & $24.0(5.0)$ \\
\hline \multicolumn{2}{|l|}{ Platelet information } \\
\hline Platelet $\times 10^{3}\left(/ \mathrm{mm}^{3}\right)$ & $266.5(70.3)$ \\
\hline PDW (fL) & 10.7 (1.9) \\
\hline MPV (fL) & $9.6(1.0)$ \\
\hline \multicolumn{2}{|l|}{ Other laboratory results } \\
\hline White blood cell $\left(/ \mathrm{mm}^{3}\right)$ & $7,495.0(2,650.0)$ \\
\hline Haemoglobin $(\mathrm{g} / \mathrm{dL})$ & $14.9(2.3)$ \\
\hline Prothrombin time (INR) & $0.9(0.1)$ \\
\hline Fasting glucose (mg/dL) & $95.5(12.8)$ \\
\hline $\mathrm{HbA} 1 \mathrm{c}$ & $5.5(0.4)$ \\
\hline Blood urea nitrogen (mg/dL) & $13.9(4.5)$ \\
\hline Creatinine $(\mathrm{mg} / \mathrm{dL})$ & $0.8(0.2)$ \\
\hline Albumin (mg/dL) & $4.5(0.5)$ \\
\hline Alkaline phosphatase (IU/L) & $70.0(26.0)$ \\
\hline Aspartate aminotransferase (IU/L) & $20.0(9.0)$ \\
\hline Alanine aminotransferase (IU/L) & $18.0(17.0)$ \\
\hline Total cholesterol (mg/dL) & $192.0(40.3)$ \\
\hline High density cholesterol (mg/dL) & $49.0(16.0)$ \\
\hline Low density cholesterol (mg/dL) & $105.0(23.2)$ \\
\hline Triglyceride (mg/dL) & $179.0(184.3)$ \\
\hline \multicolumn{2}{|c|}{ Acute reactants and disease activity indices } \\
\hline $\mathrm{ESR}(\mathrm{mm} / \mathrm{h})$ & $19.0(25.0)$ \\
\hline CRP (mg/L) & $2.5(5.3)$ \\
\hline ASDAS-ESR & $2.3(1.5)$ \\
\hline ASDAS-CRP & $2.0(1.5)$ \\
\hline BASDAI & $3.6(2.4)$ \\
\hline BAS-G & $3.0(4.0)$ \\
\hline BASFI & $1.7(3.3)$ \\
\hline
\end{tabular}

Values are expressed as median (interquartile range, IQR) and number (\%). BMl: body mass index, PDW: platelet distribution width, MPV: mean platelet volume, INR: international normalized ratio, HbA1c: haemoglobin A1c, ESR: erythrocyte sedimentation rate, CRP: C-reactive protein, ASDAS: ankylosing spondylitis disease activity score, BASDAI: bath ankylosing spondylitis disease activity index, BAS-G: bath ankylosing spondylitis patient global score, BASFI: bath ankylosing spondylitis disease activity functional index. 
positively correlated with MPV $(r=0.463, \mathrm{p}<0.001)$. However, there was no significant correlation of PDW with acute reactants and the disease activity indices of AS (Table 2). We did not include MPV in multivariate analy- sis in order not to confuse the interpretation of statistical results, because MPV is a variables closely correlated with PDW. Therefore, we could not perform a multivariate linear regression analysis.

Table 2. Univariate and multivariate analysis of either PDW or MPV and other continuous variables

\begin{tabular}{|c|c|c|c|c|c|c|c|}
\hline \multirow[b]{2}{*}{ Variable } & \multicolumn{3}{|c|}{ Univariate analysis } & \multicolumn{3}{|c|}{ Multivariate analysis } & \multirow[b]{2}{*}{ VIF } \\
\hline & $\begin{array}{l}\text { Regression } \\
\text { coefficient } \\
\text { (Crude B) }\end{array}$ & $\begin{array}{l}\text { Correlation } \\
\text { coefficient } \\
(\mathrm{R}=\beta)\end{array}$ & p-value & $\begin{array}{l}\text { Standardized } \\
\qquad \beta^{*}\end{array}$ & $\begin{array}{c}95 \% \\
\text { confidential } \\
\text { interval }\end{array}$ & p-value & \\
\hline \multicolumn{8}{|l|}{ Analysis of PDW } \\
\hline \multicolumn{8}{|l|}{ Demographic data } \\
\hline Age $(y r)$ & 0.031 & 0.205 & 0.056 & 0.098 & $-0.015,0.044$ & 0.326 & 1.093 \\
\hline Follow-up duration (yr) & 0.045 & 0.179 & 0.095 & - & - & - & - \\
\hline $\mathrm{BMI}\left(\mathrm{kg} / \mathrm{m}^{2}\right)$ & 0.053 & 0.096 & 0.893 & - & - & - & - \\
\hline \multicolumn{8}{|l|}{ Platelet information } \\
\hline Platelet $\times 10^{3}\left(/ \mathrm{mm}^{3}\right)$ & -0.011 & -0.369 & $<0.001$ & - & - & - & - \\
\hline MPV (fL) & 0.920 & 0.463 & $<0.001$ & - & - & - & - \\
\hline \multicolumn{8}{|l|}{$\begin{array}{l}\text { Acute reactants and the } \\
\text { disease activity indices }\end{array}$} \\
\hline $\mathrm{ESR}(\mathrm{mm} / \mathrm{h})$ & -0.008 & -0.078 & 0.470 & - & - & - & - \\
\hline CRP (mg/L) & -0.034 & -0.170 & 0.114 & - & - & - & - \\
\hline ASDAS-ESR & 0.091 & 0.051 & 0.635 & - & - & - & - \\
\hline ASDAS-CRP & 0.165 & 0.094 & 0.382 & -0.200 & $-0.902,0.204$ & 0.213 & 2.797 \\
\hline BASDAI & 0.193 & 0.200 & 0.062 & 0.284 & $-0.032,0.581$ & 0.079 & 2.818 \\
\hline BAS-G & 0.058 & 0.079 & 0.467 & - & - & - & - \\
\hline BASFI & -0.003 & -0.008 & 0.948 & - & - & - & - \\
\hline \multicolumn{8}{|l|}{ Analysis of MPV } \\
\hline \multicolumn{8}{|l|}{ Demographic data } \\
\hline Age $(y r)$ & 0.021 & 0.274 & 0.010 & 0.129 & $-0.006,0.025$ & 0.209 & 1.176 \\
\hline Follow-up duration (yr) & 0.037 & 0.293 & 0.006 & 0.175 & $-0.003,0.048$ & 0.089 & 1.170 \\
\hline BMl $\left(\mathrm{kg} / \mathrm{m}^{2}\right)$ & 0.032 & 0.114 & 0.290 & - & - & - & - \\
\hline \multicolumn{8}{|l|}{ Platelet information } \\
\hline Platelet $\times 10^{3}\left(/ \mathrm{mm}^{3}\right)$ & -0.003 & -0.236 & 0.027 & - & - & - & - \\
\hline PDW (fL) & 0.233 & 0.463 & $<0.001$ & - & - & - & - \\
\hline \multicolumn{8}{|l|}{$\begin{array}{l}\text { Acute reactants and the } \\
\text { disease activity indices }\end{array}$} \\
\hline $\mathrm{ESR}(\mathrm{mm} / \mathrm{h})$ & 0.001 & 0.018 & 0.869 & - & - & - & - \\
\hline CRP (mg/L) & -0.022 & -0.218 & 0.041 & - & - & - & - \\
\hline ASDAS-ESR & 0.075 & 0.083 & 0.440 & - & - & - & - \\
\hline ASDAS-CRP & 0.123 & 0.140 & 0.193 & 0.020 & $-0.261,0.296$ & 0.901 & 2.882 \\
\hline BASDAI & 0.084 & 0.173 & 0.108 & 0.068 & $-0.122,0.189$ & 0.672 & 2.947 \\
\hline BAS-G & 0.051 & 0.039 & 0.198 & - & - & - & - \\
\hline BASFI & 0.018 & 0.084 & 0.491 & - & - & - & - \\
\hline
\end{tabular}

Multivariate analyses for PDW were adjusted for age, ASDAS-CRP and BASDAI. We did not include MPV in multivariate analysis in order not to confound the interpretation of statistical results, because MPV is a variable closely correlated with PDW. Multivariate analyses for MPV were adjusted for age, disease duration, ASDAS-CRP and BASDAI. We did not include PDW in multivariate analysis in order not to confound the interpretation of statistical results, because PDW is a variable closely correlated with MPV. PDW: platelet distribution width, MPV: mean platelet volume, VIF: variance inflation factor, BMI: body mass index, ESR: erythrocyte sedimentation rate, CRP: C-reactive protein, ASDAS: ankylosing spondylitis disease activity score, BASDAI: bath ankylosing spondylitis disease activity index, BAS-G: bath ankylosing spondylitis patient global score, BASFI: bath ankylosing spondylitis disease activity functional index, -: not applicable. 


\section{Univariate and multivariate analyses of MPV and other variables}

We analysed the association of MPV with acute phase reactants and the disease activity indices of AS. Univariate linear regression analysis discovered that MPV was inversely correlated with platelet count $(r=-0.236$, $\mathrm{p}=0.027)$ and positively correlated with PDW $(r=0.463$, $\mathrm{p}<0.001)$. Also MPV was significantly correlated with age and the follow-up duration $(r=0.274, \mathrm{p}=0.010$, and $r=0.293, \mathrm{p}=0.006$ ). Among acute reactants and the disease activity indices of AS, only CRP was negatively correlated with MPV $(r=-0.218, \mathrm{p}=0.041)$ (Table 2$)$. Similar to the analysis of PDW, we did not include PDW in multivariate analysis in order not to confound the interpretation of statistical results, because PDW is a variables closely correlated with MPV. On multivariate linear regression analysis, only the follow-up duration was significantly correlated with MPV $(\beta=0.224, \mathrm{p}=0.044)$ (Table 2).

\section{DISCUSSION}

The aim of this study was to confirm whether PDW and MPV can reflect disease activity indices of AS in patients without abnormal laboratory results or medication conditions to affect PDW and MPV levels, because there have been discrepancies among previous studies, the positive vs. negative association of MPV with AS activity [18-20]. Meanwhile, other previous study reported that PDW and MPV were not correlated with AS activity [21,22]. We assumed that the diverse confounding factors to affect PDW and MPV levels might result in these discrepancies [11-17,24-26]. With these reasons, in the present study, we excluded patients with AS who had abnormal laboratory results, and who had medical conditions such as hematologic diseases or history of medication administered affecting PDW and MPV such as antiplatelets [25,28] (data not shown). And in this study, we found that PDW and MPV were not associated with not only acute reactants, but also disease activity indices of AS after the adjustment of the confounding factors.

We investigated that PDW an MPV may differ between active and inactive groups based on ASDAS-ESR and ASDAS-CRP. When we divided 88 AS patients into the two groups according to ASDAS-ESR of 2.1, 59 patients were assigned to active group. The two groups had statistically even demographic data. We found no significant differences in both PDW and MPV between the groups.
Also, when we divided $88 \mathrm{AS}$ patients into the two groups according to ASDAS-CRP of 2.1, 45 patients were assigned to active group. There were no significant differences in demographic data between the two groups. Similar to the results based on ASDAS-ESR, we observed no significant differences in both PDW and MPV between the groups. Taken together, we concluded that PDW and MPV were not potent surrogate markers to reflect AS activity, under the strict control of the confounding factors to affect MPV and PDW levels. The strength of our study is to strictly exclude patients with AS, who had abnormal laboratory results, and who had medical conditions or history of medication administered affecting PDW and MPV levels. Our study had several issues. The serial follow-up results of PDW and MPV as well as the disease activity indices of AS were not available due to a cross-sectional study. Also the number of patients with AS was not large enough to validate our results. We plan to serially measure PDW and MPV along with the disease activity indices of AS in the more number of patients.

\section{CONCLUSION}

The aim of this study was to confirm whether PDW and MPV can reflect disease activity indices of AS in patients without abnormal laboratory results or medication conditions to affect PDW and MPV levels. And we found that PDW and MPV were not potent surrogate markers to reflect AS activity, under the strict control of the confounding factors.

\section{CONFLICT OF INTEREST}

No potential conflict of interest relevant to this article was reported.

\section{REFERENCES}

1. Sieper J. New treatment targets for axial spondyloarthritis. Rheumatology (Oxford) 2016;55(suppl 2):ii38-ii42.

2. Dougados M, Gueguen A, Nakache JP, Velicitat P, Zeidler $\mathrm{H}$, Veys $\mathrm{E}$, et al. Clinical relevance of C-reactive protein in axial involvement of ankylosing spondylitis. J Rheumatol 1999;26:971-4.

3. Pedersen SJ, Sørensen IJ, Garnero P, Johansen JS, Madsen OR, Tvede N, et al. ASDAS, BASDAI and different treatment responses and their relation to biomarkers of inflammation, cartilage and bone turnover in patients with axial spondyloarthritis treated with TNF $\alpha$ inhibitors. Ann Rheum Dis 2011;70:1375-81.

4. Garrett S, Jenkinson T, Kennedy LG, Whitelock H, Gaisford 
P, Calin A. A new approach to defining disease status in ankylosing spondylitis: the Bath Ankylosing Spondylitis Disease Activity Index. J Rheumatol 1994;21:2286-91.

5. Calin A, Garrett S, Whitelock H, Kennedy LG, O'Hea J, Mallorie $\mathrm{P}$, et al. A new approach to defining functional ability in ankylosing spondylitis: the development of the Bath Ankylosing Spondylitis Functional Index. J Rheumatol 1994;21:2281-5.

6. Jones SD, Steiner A, Garrett SL, Calin A. The bath ankylosing spondylitis patient global score (BAS-G). Br J Rheumatol 1996;35:66-71.

7. Jenkinson TR, Mallorie PA, Whitelock HC, Kennedy LG, Garrett SL, Calin A. Defining spinal mobility in ankylosing spondylitis (AS). The Bath AS Metrology Index. J Rheumatol 1994;21:1694-8.

8. van der Heijde D, Lie E, Kvien TK, Sieper J, Van den Bosch F, Listing J, et al. ASDAS, a highly discriminatory ASAS-endorsed disease activity score in patients with ankylosing spondylitis. Ann Rheum Dis 2009;68:1811-8.

9. Leader A, Pereg D, Lishner M. Are platelet volume indices of clinical use? A multidisciplinary review. Ann Med 2012; 44:805-16.

10. Hoffmann JJ. Reticulated platelets: analytical aspects and clinical utility. Clin Chem Lab Med 2014;52:1107-17.

11. Esen B, Atay AE, Gunoz N, Gokmen ES, Sari H, Cakir I, et al. The relation of mean platelet volume with microalbuminuria and glomerular filtration rate in obese individuals without other metabolic risk factors: the role of platelets on renal functions. Clin Nephrol 2015;83:322-9.

12. Kurt M, Onal IK, Sayilir AY, Beyazit Y, Oztas E, Kekilli M, et al. The role of mean platelet volume in the diagnosis of hepatocellular carcinoma in patients with chronic liver disease. Hepatogastroenterology 2012;59:1580-2.

13. Ju HY, Kim JK, Hur SM, Woo SA, Park KA, Park MY, et al. Could mean platelet volume be a promising biomarker of progression of chronic kidney disease? Platelets 2015;26: 143-7.

14. Karabacak M, Dogan A, Turkdogan AK, Kapci M, Duman A, Akpinar O. Mean platelet volume is increased in patients with hypertensive crises. Platelets 2014;25:423-6.

15. Varol E, Ozaydin M. Mean platelet volume measurement in patients with hypercholesterolemia: a methodological issue. Angiology 2013;64:626.

16. Wang X, Xu XL, Li XM, Zhao R, Yang X, Cong HL. Diagnostic value of mean platelet volume combined with troponin i for acute coronary syndrome. Am J Med Sci 2016;352:159-65.
17. Tecer D, Sezgin M, Kanık A, İncel NA, Çimen ÖB, Biçer A, et al. Can mean platelet volume and red blood cell distribution width show disease activity in rheumatoid arthritis? Biomark Med 2016;10:967-74.

18. Kisacik B, Tufan A, Kalyoncu U, Karadag O, Akdogan A, Ozturk MA, et al. Mean platelet volume (MPV) as an inflammatory marker in ankylosing spondylitis and rheumatoid arthritis. Joint Bone Spine 2008;75:291-4.

19. Şahin A, Yetişgin A, Şahin M, Durmaz Y, Cengiz AK. Can mean platelet volume be a surrogate marker of inflammation in rheumatic diseases? West Indian Med J 2015; 65:165-9.

20. Yazici S, Yazici M, Erer B, Erer B, Calik Y, Bulur S, et al. The platelet functions in patients with ankylosing spondylitis: anti-TNF-alpha therapy decreases the mean platelet volume and platelet mass. Platelets 2010;21:126-31.

21. Sezgin M, Tecer D, Kanık A, Kekik FS, Yeşildal E, Akaslan E, et al. Serum RDW and MPV in ankylosing spondylitis: Can they show the disease activity? Clin Hemorheol Microcirc 2017;65:1-10.

22. Resorlu H, Resorlu M, Gokmen F, Akbal A, Adam G, Komurcu E, et al. Association between mean platelet volume and bone mineral density in patients with ankylosing spondylitis and diagnostic value of diffusion-weighted magnetic resonance imaging. J Phys Ther Sci 2015;27:1137-40.

23. van der Linden S, Valkenburg HA, Cats A. Evaluation of diagnostic criteria for ankylosing spondylitis. A proposal for modification of the New York criteria. Arthritis Rheum 1984;27:361-8.

24. Cho SY, Jeon YL, Kim W, Kim WS, Lee HJ, Lee WI, et al. Mean platelet volume and mean platelet volume/platelet count ratio in infective endocarditis. Platelets 2014;25:55961.

25. Bessman JD, Williams LJ, Gilmer PR Jr. Platelet size in health and hematologic disease. Am J Clin Pathol 1982; 78:150-3.

26. Kaushansky K. The molecular mechanisms that control thrombopoiesis. J Clin Invest 2005;115:3339-47.

27. Lee SW, Park HJ, Kim BK, Han KH, Lee SK, Kim SU, et al. Leflunomide increases the risk of silent liver fibrosis in patients with rheumatoid arthritis receiving methotrexate. Arthritis Res Ther 2012;14:R232.

28. De Luca G, Secco GG, Iorio S, Verdoia M, Bellomo G, Marino P. Short-term effects of aspirin and clopidogrel on mean platelet volume among patients with acute coronary syndromes. A single-center prospective study. Blood Coagul Fibrinolysis 2012;23:756-9. 